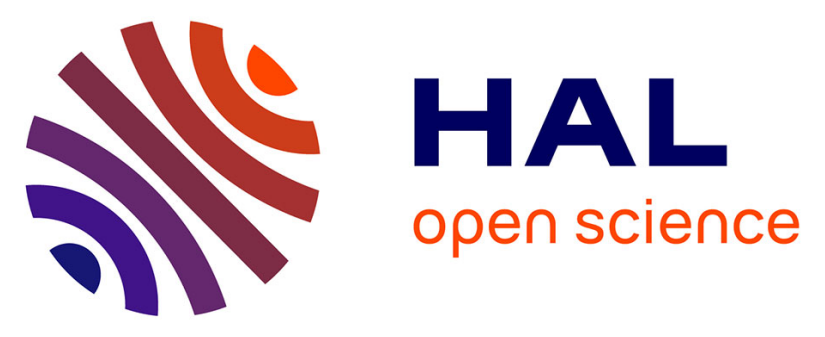

\title{
SERB, a nano-satellite dedicated to the Earth-Sun relationship
}

Mustapha Meftah, Étienne Bamas, Pierre Cambournac, Philippe Cherabier, Romain Demarets, Gaspard Denis, Axel Dion, Raphaël Duroselle, Florence Duveiller, Laetitia Eichner, et al.

\section{To cite this version:}

Mustapha Meftah, Étienne Bamas, Pierre Cambournac, Philippe Cherabier, Romain Demarets, et al.. SERB, a nano-satellite dedicated to the Earth-Sun relationship. SPIE 9838, Sensors and Systems for Space Applications IX, Apr 2016, Baltimore, United States. pp.98380T, 10.1117/12.2222660 . insu-01321873

\section{HAL Id: insu-01321873 \\ https://hal-insu.archives-ouvertes.fr/insu-01321873}

Submitted on 26 May 2016

HAL is a multi-disciplinary open access archive for the deposit and dissemination of scientific research documents, whether they are published or not. The documents may come from teaching and research institutions in France or abroad, or from public or private research centers.
L'archive ouverte pluridisciplinaire HAL, est destinée au dépôt et à la diffusion de documents scientifiques de niveau recherche, publiés ou non, émanant des établissements d'enseignement et de recherche français ou étrangers, des laboratoires publics ou privés. 


\title{
SERB, a nano-satellite dedicated to the Earth-Sun relationship
}

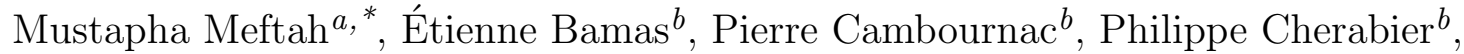 \\ Romain Demarets $^{b}$, Gaspard Denis ${ }^{b}$, Axel Dion ${ }^{b}$, Raphaël Duroselle ${ }^{b}$, Florence Duveiller ${ }^{b}$, \\ Laetitia Eichner $^{b}$, Dimitri Lozeve ${ }^{b,}$, Guillaume Mestdagh $^{b}$, Antoine Ogier $^{b}$, Romane Oliverio $^{b}$, \\ Thibault Receveur ${ }^{b}$, Camille Souchet ${ }^{b}$, Pierre Gilbert ${ }^{a}$, Germain Poiet $^{a}$, \\ Alain Hauchecorne ${ }^{a}$, Philippe Keckhut ${ }^{a}$, and Alain Sarkissian ${ }^{a}$ \\ ${ }^{a}$ Université Paris Saclay, Université Paris VI - Pierre et Marie Curie, CNRS/INSU, \\ LATMOS-IPSL, 11 Boulevard d'Alembert, 78280 Guyancourt, France \\ ${ }^{b}$ École polytechnique, Route de Saclay, 91128 Palaiseau, France
}

\begin{abstract}
The Solar irradiance and Earth Radiation Budget (SERB) mission is an innovative proof-of-concept nanosatellite, with three ambitious scientific objectives. The nano-satellite aims at measuring on the same platform the absolute value of the total solar irradiance (TSI) and its variability, the ultraviolet (UV) solar spectral variability, and the different components of the Earth radiation budget. SERB is a joint project between CNES (Centre National d'Études Spatiales), École polytechnique, and LATMOS (Laboratoire Atmosphères, Milieux, Observations Spatiales) scheduled for a launch in 2020-2021. It is a three-unit CubeSat (X-CubeSat II), developed by students from École polytechnique. Critical components of instrumental payloads of future large missions (coatings, UV filters, etc.) can acquire the technical maturity by flying in a CubeSat. Nano-satellites also represent an excellent alternative for instrumentation testing, allowing for longer flights than rockets. Moreover, specific scientific experiments can be performed by nano-satellites. This paper is intended to present the SERB mission and its scientific objectives.
\end{abstract}

Keywords: Nano-satellites, Sun-Earth relationship, total solar irradiance, ultraviolet solar irradiance, Earth radiation budget.

\section{INTRODUCTION}

The space industry has recently seen a surge in the development of small satellite technology. Micro-satellites $(10 \mathrm{~kg}-150 \mathrm{~kg})$, nano-satellites $(1 \mathrm{~kg}-10 \mathrm{~kg})$, and even pico-satellites (less than $1 \mathrm{~kg}$ ) have all been considered in many fields and for various objectives, from scientific research to technology demonstration, including Earth observation and telecommunications. Small satellites have allowed universities to test new technologies and to explore scientific hypotheses in space. Groups of students with support and guidance of specialists in space systems have been able to realise and control all aspects of the mission, from the initial design to the groundbased control station. This was possible for a number of reasons. First, small spacecraft benefitted from recent advances in miniaturisation and integration. One now has the capacity to build lighter and smaller instruments with nearly equivalent performances, and to integrate them into a single platform. Moreover, most applications of nano-satellites have higher risk tolerance than high-budget missions, and can thus make use of commercial off-the-shelf components and even in some cases of consumer electronics, whose performances increased greatly in recent years. The standardisation of small spacecraft initiated by the CubeSat project of California Polytechnic State University (Cal Poly $)^{1}$ and Stanford University ${ }^{2}$ has also helped the development of components ready to be integrated directly into the standard platform, which consists in small cubic units with a size of $10 \times 10 \times 10 \mathrm{~cm}^{3}$. These cubic units can be combined in a three-unit $(3 \mathrm{U})$ nano-satellite $\left(10 \times 10 \times 30 \mathrm{~cm}^{3}\right)$. Small spacecraft can also leverage existing launch vehicles used for larger payloads ("piggy-back"), or be deployed from the International

\footnotetext{
* Corresponding authors

E-mail address: Mustapha.Meftah@latmos.ipsl.fr

E-mail address: dimitri.lozeve@polytechnique.edu
} 
Space Station (ISS), which helps reduce costs. The total cost of an industrial typical 3U CubeSat is normally between 100 and $200 \mathrm{~K} €$ but can go up to $1,000 \mathrm{~K} €$ for more sophisticated payloads requiring specific capacities (high precision of the satellite's attitude and orbit control system, thermal control with high accuracy, etc.) such as the Solar irradiance and Earth Radiation Budget (SERB). All of these advances, along with fractionated mission architecture, particularly adapted to group of students, and shorter lead times, have allowed nanosatellite technology to skyrocket in universities and research laboratories. In France, the JANUS project (Jeunes en Apprentissage pour la réalisation de Nanosatellites au sein des Universités et des écoles de l'enseignement Supérieur), sponsored by the French space agency (CNES), promotes space activities in universities by supporting complete projects with training, help in the development of some difficult subsystems, and partial financing. The SERB nano-satellite also called X-CubeSat II is a part of the JANUS project. Following sections present the scientific objectives of the SERB mission, the current definition of the nano-satellite, and a summary on the technologies developments accompanying the program.

\section{SERB SCIENTIFIC OBJECTIVES}

The SERB mission represents one of the first attempts to perform simultaneous measurements with a nanosatellite dedicated to study the Sun and the Earth. The scientific objectives of the SERB mission are:

- To measure the total solar irradiance (TSI) variability and to extend previous measurements,

- To improve the knowledge of the absolute value of the TSI with an accuracy better than $0.5 \mathrm{Wm}^{-2}$,

- To establish a radiation budget of the Earth with an accuracy better than 5\%,

- And to monitor the solar spectral irradiance (SSI) at $215 \mathrm{~nm}$ (Herzberg solar continuum).

\subsection{The TSI variability and its absolute value}

Long-term monitoring of the Essential Climate Variable (ECV) TSI is important in order to understand the change of climate with time. The TSI is the main external source of heat of the Earth. However, it has not been proven conclusively that the TSI had a direct influence on recent global warming. ${ }^{3,4}$ In order to understand how the TSI has influenced the Earth's climate, models have been developed to reconstruct the variations of the TSI on various geological timescales, and particularly during the Holocene, ${ }^{5}$ which began 12,000 to 11,500 years ago. Current models use a variety of parameters, including the concentration in cosmogenic isotopes $\left({ }^{14} \mathrm{C}\right.$ and $\left.{ }^{10} \mathrm{Be}\right)$, from which one can deduce the evolution of the solar surface magnetic field. The latter is then used to reconstruct the total solar irradiance. ${ }^{5}$ TSI measurements are required to verify the models and the physical mechanisms responsible for irradiance variations. Thus, models must reproduce all available observations. Since 1978, the absolute value of the TSI and its temporal variation have been measured from space that allowed scientists to acquire a better understanding of variations in the TSI. The precise measurement of the TSI is historically foremost. Prior to the launch of the Solar Radiation and Climate Experiment (SORCE) spacecraft in January 2003, the consensus absolute value of the TSI was close to $1365.4 \mathrm{Wm}^{-2}$. The Total Irradiance Monitor (TIM) instrument onboard $\mathrm{SORCE}^{6}$ measured deviating values around $1361 \mathrm{Wm}^{-2}$. This result was independently obtained by the PREcision MOnitor Sensor (PREMOS) instrument onboard PICARD. ${ }^{7}$ In addition, the measurements of SOlar VAriability Picard (SOVAP) radiometer ${ }^{8}$ yielded a TSI value quite close to TIM and PREMOS results $\left(\sim 1362 \mathrm{Wm}^{-2}\right.$ for the mean annual TSI, representative of the 2008 solar minimum). The total solar irradiance since 1976 at a mean Earth-Sun distance of one astronomical unit (1 AU) is shown in Figure 1. This curve is obtained with data of the Spectral And Total Irradiance REconstruction for the Satellite era (SATIRE-S) semi-empirical model. SATIRE-S ${ }^{9}$ is a semi-empirical model, which provides reconstructions of TSI. The Active Cavity Radiometer Irradiance Monitor (ACRIM) TSI composite (http://acrim.com/) and the "Physikalisch-Meteorologisches Observatorium Davos" (PMOD) TSI composite appear to be about $0.25 \mathrm{Wm}^{-2}$ less in 2008 than in 1996 and are consistent with the SATIRE-S reconstructed model of the TSI. In contrast, the Differential Absolute Radiometer (DIARAD) ${ }^{10}$ as part of the Variability of Irradiance and Gravity Oscillations (VIRGO) experiment on the Solar and Heliospheric Observatory (SoHO) suggests that the TSI is higher in 2008 than in 1996. Therefore, the 'true values' of TSI during solar minima (1976, 1986, 1996, and 2008) as seen in Figure 1 are questionable. The SATIRE-S TSI semi-empirical model suggests a decrease of the total 
solar irradiance of $\sim-0.5 \mathrm{Wm}^{-2}$ over the last 40 years. Thus, new observations are required to advance our understanding of the TSI variability. It would be useful to develop a space system to monitor the TSI during a long period (70-100 year Gleissberg cycle). The use of multiple nano-satellites based on the same technology offers a unique opportunity to achieve this goal. Indeed, several nano-satellites launched at different periods can gather TSI data over time with a recovery period. Scientific requirements are a TSI measurements uncertainty (absolute determination) of $\pm 0.5 \mathrm{Wm}^{-2}( \pm 367$ parts per million $(\mathrm{ppm}))$, a measurements repeatability of $\pm 0.01 \mathrm{Wm}^{-2}$ $( \pm 7 \mathrm{ppm})$, and a long-term stability better than $\pm 0.1 \mathrm{Wm}^{-2}( \pm 73 \mathrm{ppm})$. Thus, the innovative proof-of-concept SERB nano-satellite is designed to realise TSI measurements during a short period (1-2 years) and to validate the multiple nano-satellites principle.

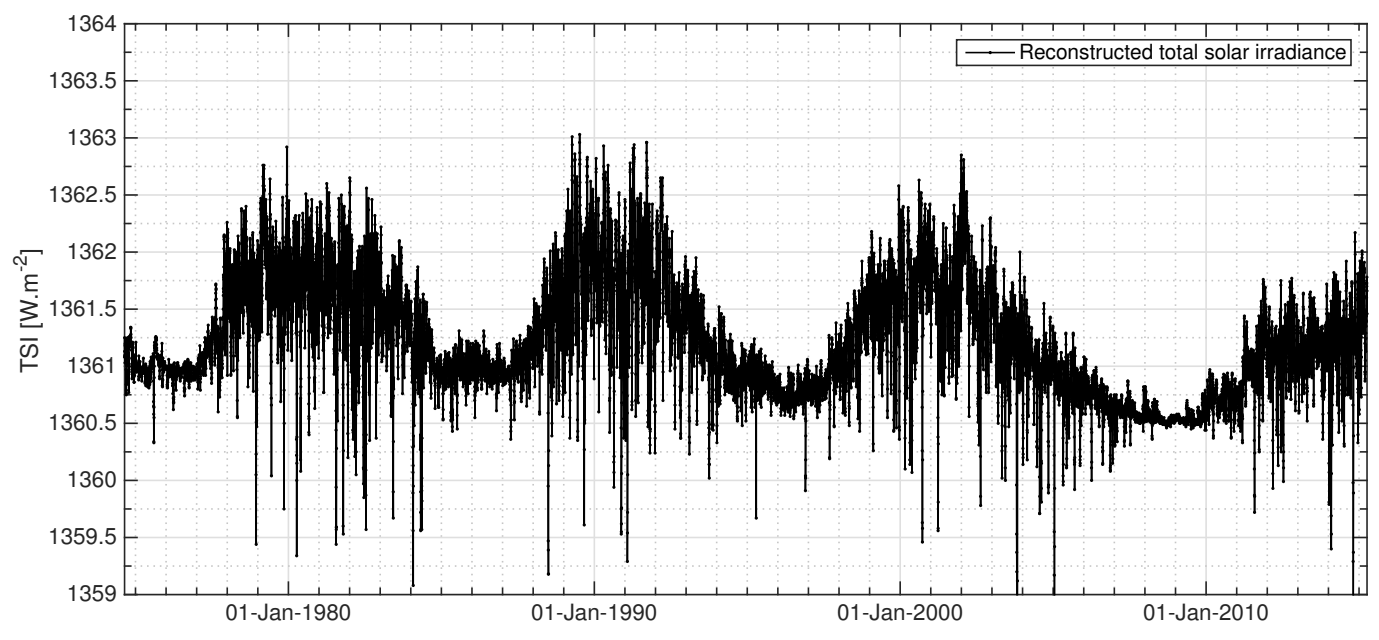

Figure 1. TSI time series (SATIRE-S reconstruction) that highlights differences for solar minima $\left(\sim-0.5 \mathrm{Wm}^{-2}\right.$ difference between solar cycle 21 started in May 1976 and solar cycle 24 started in January 2008).

\subsection{The radiation budget of the Earth}

The global energy balance for the Earth-atmosphere system is also very important to understand. Of the $\sim 342 \mathrm{Wm}^{-2}$ incoming solar radiation (Shortwave Radiation), $\sim 67 \mathrm{Wm}^{-2}$ are absorbed during passage through the atmosphere (clouds, molecules). A total of $\sim 107 \mathrm{Wm}^{-2}$ (Reflected Short-wave Radiation) is reflected back to space (clouds, Earth's surface, and scattering by molecules) in the 0.2 to $3 \mu \mathrm{m}$ wavelength band. Shortwave radiation is a term used to describe radiant energy with wavelengths in the near-UV, the Visible (VIS), and the Near-Infrared (NIR) spectra. The remaining $\sim 168 \mathrm{Wm}^{-2}$ are absorbed at the Earth's surface. In order to maintain a stable climate, the Earth must be in energetic equilibrium between the radiation it receives from the Sun and the radiation it emits out to space. Outgoing Long-wave Radiation (OLR radiation in the 3 to $100 \mu m$ wavelength band) is the energy leaving the Earth as infrared radiation at low energy (mean value of $235 \mathrm{Wm}^{-2}$ emitted). Figure 2 displays the spatial distribution of OLR (February 2016). OLR is affected by the Earth's skin temperature, skin surface emissivity, atmospheric temperature, water vapor profile, clouds and dust in the atmosphere, which tend to reduce it below clear sky values. Greenhouse gases, such as methane (CH4), nitrous oxide (N2O), water vapor $(\mathrm{H} 2 \mathrm{O})$ and carbon dioxide (CO2), absorb certain wavelengths of OLR adding heat to the atmosphere, which in turn causes the atmosphere to emit more radiation. The effect of clouds on radiation budgets at the top of atmosphere (TOA) derived from the Earth Radiation Budget Experiment $(\mathrm{ERBE})^{11}$ has been widely used to validate climate models and to improve cloud parameterisation schemes. If we consider the long-term equilibrium of the global Earth radiation budget, it should be in equilibrium. The quantity of the solar energy received at the top atmosphere should be equal to the OLR radiation and to the solar energy reflected by the Earth surface, the clouds, and the atmosphere. Due to the increase of greenhouse gases, the total energy stored in the atmosphere and the oceans is increasing and there is a small imbalance, estimated at $0.6 \mathrm{Wm}^{-2}$ (Hansen et al., ${ }^{12}$ 2011) between the incoming and the outgoing energy. However it is an extremely 
difficult challenge to measure this small difference. On a local or regional scale the radiation budget is not in equilibrium. It depends on the latitude, season, surface albedo, and clouds. The energy budget is positive in the tropics and negative at high latitudes especially in winter. The imbalance is compensated by the transport of heat from warm to cold regions. It is of great importance to be able to measure this imbalance for the study of regional climate changes. Global Climate Models (GCMs) are consistent for the prediction of the evolution of the global surface temperature but differ from each other's for the predictions of climate change at regional scale. This is probably due to an imperfect representation of the clouds and aerosols that result in uncertainties in the local radiation budget. The future nano-satellite data will be compared with the output of the GCMs to identify where the differences in the radiation budget occur. Planetary Infrared for the Earth (or Outgoing Long-wave Radiation) and Earth Reflected Solar (Reflected Short-wave Radiation) are a complex function of the local time, the local latitude, the geographical situation and the atmospheric conditions. Using the temperatures (housekeeping of the spacecraft) of thermal sensors measured in space, we can get these informations. Thus, the innovative proof-of-concept SERB nano-satellite is designed to realise outgoing long-wave radiation and reflected short-wave radiation measurements during a short period (1-2 years) and to validate the scientific requirements (accuracy better than $\sim 5 \%$ ). It could be particularly advantageous to increase the coverage in local time and latitude using a constellation of SERB nano-satellites around the Earth to establish a radiation budget with a high accuracy.

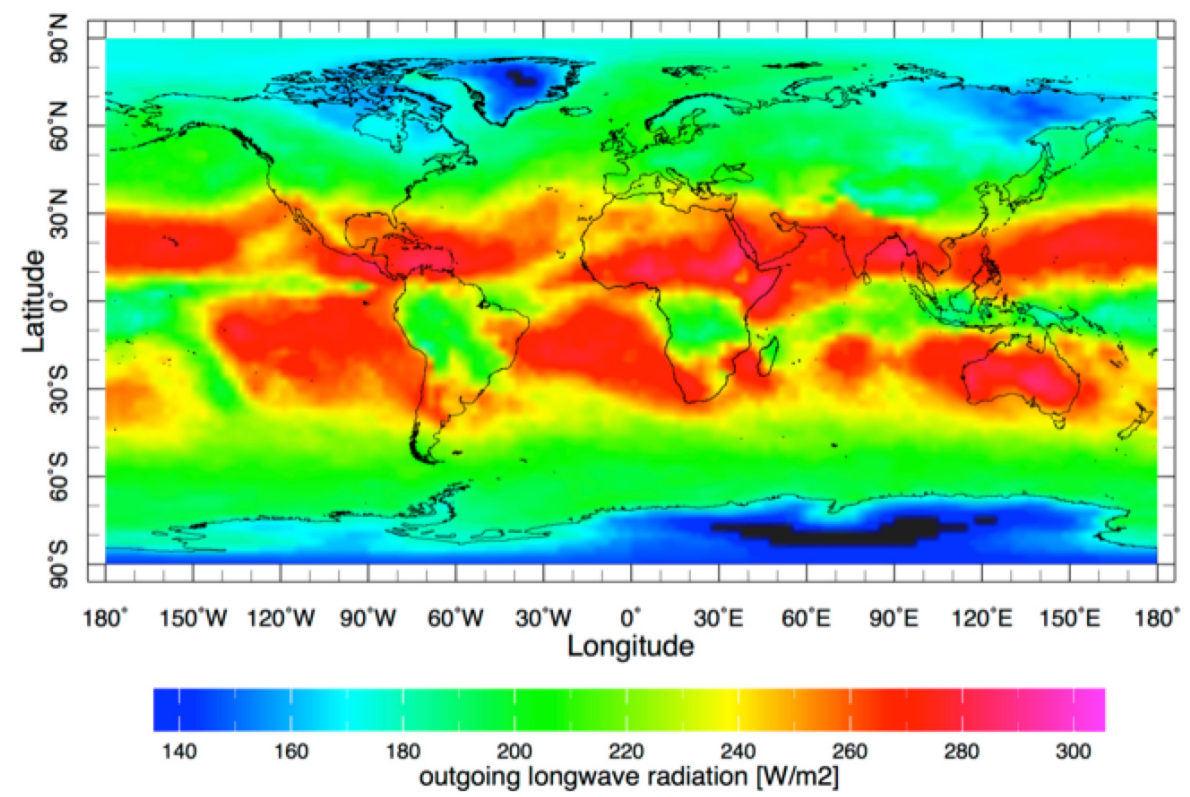

Figure 2. OLR published by the National Oceanic and Atmospheric Administration (NOAA) - February 2016.

\subsection{The SSI variability at $215 \mathrm{~nm}$}

There is a need for a thorough understanding of how the Sun affects climate. This is important because it has long and short term influences and we need to know how these interact with anthropogenic effects. It is also important to understand natural factors in climate variability to give a basis upon which its future state might be predicted. Thus, the measurement of the solar spectral irradiance is vital for understanding how solar variability impacts climate. Among them, UV solar variability is probably the most important, but the mechanisms involved are still poorly understood due to the complexity of interactions occurring between the various atmospheric layers from the ground to the thermosphere. As example, solar UV at $\sim 200 \mathrm{~nm}$ heats the ozone locally and create defects/anomalies on the propagation of the zonal planetary wave that will, in turn, affect the tropospheric circulation. Recent studies (Ineson et al., 2011, Martin-Puertas et al., ${ }^{13}$ 2012) confirmed this mechanism. Therefore, precise SSI variability measurements in the UV are required to quantify the topdown mechanism amplifying UV solar forcing on the climate despite the fact that the UV range $(115.5-400 \mathrm{~nm})$ 
represents only $\sim 7.7 \%$ of TSI. Moreover, UV solar variability can vary significantly during solar cycles as shown in Figure 3. Large changes in solar UV radiation can indirectly affect climate by inducing atmospheric changes. ${ }^{13}$

In order to represent correctly the solar forcing, it is necessary to take into account the upper layers of the atmosphere that are most sensitive to the solar input and their interaction with the lower atmosphere. The radiation budget of the middle atmosphere is controlled by the ozone layer. Ozone is formed by photo-dissociation of $\mathrm{O}_{2}$ by the solar UV at wavelengths shorter than $240 \mathrm{~nm}$. The rate of formation of ozone is directly related to the intensity of solar UV modulated by the 11-year solar cycle with a 5 to $10 \%$ amplitude below $240 \mathrm{~nm}$ (example at $215 \mathrm{~nm}$, see Figure 3). This induces measurable changes in the total column of stratospheric ozone. The change in UV and visible solar heating by the ozone layer induces changes in stratospheric temperature, pressure and winds and in propagation of atmospheric waves that controls the dynamical interaction between the stratosphere and the troposphere. The solar forcing can modulate for instance the frequency of wintertime sudden stratospheric warmings, very spectacular dynamical events with up to $50 \mathrm{~K}$ temperature increase in the Arctic stratosphere. The solar heating by stratospheric ozone is also sensitive to changes in surface and clouds albedo as the albedo decrease due to the sea-ice melting in the Arctic Ocean.

The SERB nano-satellite aims to measure the UV part of the spectrum, which are the most sensitive to solar variability. The far UV is the only wavelength band with energy absorbed in the high atmosphere (stratosphere), in the ozone (Herzberg solar continuum, 200-242 nm) and oxygen bands, and its high variability is most probably at the origin of a climate influence (UV affects stratospheric dynamics and temperatures, altering interplanetary waves and weather patterns both poleward and downward to the lower stratosphere and tropopause regions). Recent measurements at the time of the recent solar minimum (Haigh et al., ${ }^{14}$ 2010) suggest that variations in the UV may be larger than previously assumed what implies a very different response in both stratospheric ozone and temperature.

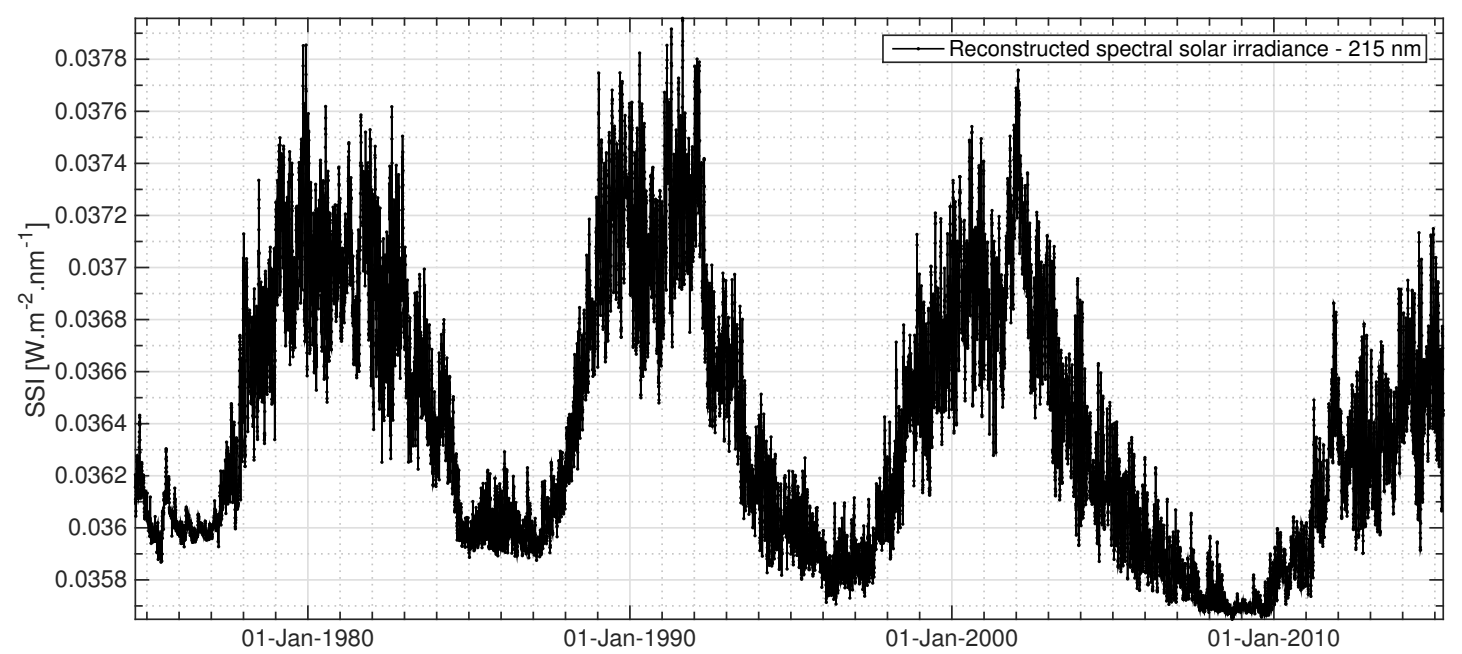

Figure 3. SSI time series (SATIRE-S reconstruction) at $215 \mathrm{~nm}$ that highlights a modulation of the 11-year solar cycle with a $5 \%$ amplitude. A decrease of SSI is observed at each solar minima since 1976 such as TSI.

\section{THE NANO-SATELLITE}

The SERB nano-satellite is a three-unit (3U) CubeSat. A preliminary configuration of the nano-satellite system is shown in Figure 4. The science payload will take up one unit on the three with the different instruments. The two other units contain the platform. The key element of the mission is the space segment, containing the nano-satellite $\left(10 \times 30 \times 50 \mathrm{~cm}^{3}\right.$ deployed, $4.5 \mathrm{~kg}$ maximum, and $13.6 \mathrm{~W}$ power consumption $)$ that includes the payload and the avionics. Main elements are batteries, electronic power supply board, S-band board, on board computer (OBC), global positioning system (GPS) board, CubeADCS 3-Axis bundle (attitude determination 
and control system), two S-band patch antennas, payload board, payload and harness, structure, deployable solar panels, harness, etc. All these components (Figure 5) will be integrated in the nano-satellite. Table 1 summarises the main characteristics of the SERB nano-satellite. There is no electronic boards on the payload unit. The electronic board of the payload is included in the platform (bottom location of the $3 \mathrm{U}$ nano-satellite). There is a PC104 interface module for all the electronic boards of the nano-satellite.

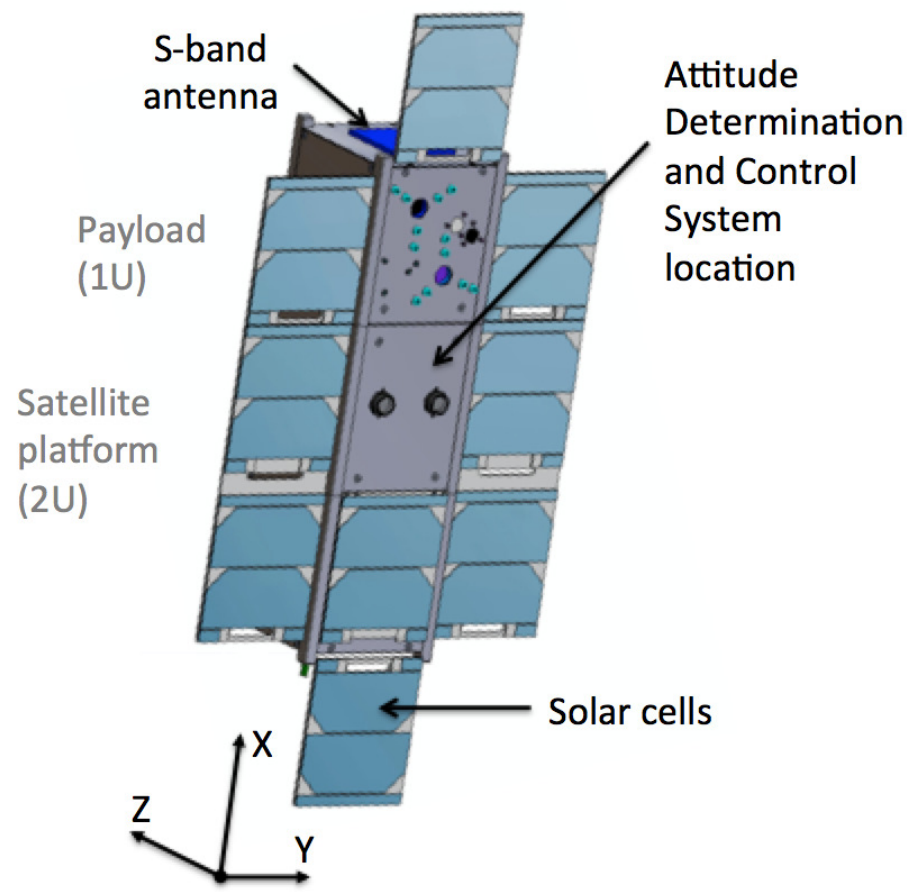

Figure 4. General layout of the SERB nano-satellite.

Table 1. SERB three-unit CubeSat main characteristics.

\begin{tabular}{|l|l|}
\hline Parameter & Value (remark) \\
\hline Volume (stowed position) & $10(\mathrm{~d}) \times 10(\mathrm{w}) \times 30(\mathrm{~h}) \mathrm{cm}^{3}$ \\
Volume (deployed) & $10(\mathrm{~d}) \times 30(\mathrm{w}) \times 50(\mathrm{~h}) \mathrm{cm}^{3}$ \\
Mass & $4.5 \mathrm{~kg}($ maximum with margin) \\
Orbit average power generated & $18.9 \mathrm{~W}$ (without eclipses) \\
Electrical power consumption & $13.6 \mathrm{~W}$ \\
Field of view (payload) & $180^{\circ}$ \\
Data storage & 1 Gbyte \\
Downlink speed (S-band) & From $10 \mathrm{kbps}$ to 1 Mbps (megabits per second) \\
Uplink speed & $8 \mathrm{kbps}$ to $256 \mathrm{kbps}$ \\
Ground station contact time & $\sim 10$ minutes per passage $(\sim 6$ passages per day) \\
Downlink volume (S-band) & $\sim 400$ Mbyte per day \\
Uplink volume & $\sim 0.3$ Mbyte per day \\
Mission modes & Sun pointing, Nadir pointing, and stars pointing \\
Mission lifetime & One year \\
\hline
\end{tabular}

\section{- The stringent pointing requirements of the nano-satellite:}

The SERB nano-satellite's pointing accuracy will be better than $0.2^{\circ}$ along the axis of the Sun and $0.4^{\circ}$ towards nadir at minimum. Nominally, the payload will be Sun pointing (-Z-axis) in order to make solar measurements 
all the time. Once every one month, for a few orbits, the payload will be pointed towards stars (-Z-axis) in order to make deep space measurements. Each three months, the main payload surface will be nadir pointing (-Z-axis) in order to make precise measurements towards the Earth.

\section{- The parameters of the orbit:}

In a Sun-synchronous orbit (SSO), though, the satellite passes over the same part of the Earth at roughly the same local time each day. This can make communication and various forms of data collection very convenient. SERB will be in orbit $680 \mathrm{~km}$ above the Earth, at an angle of inclination of 98.8 degrees to the equator as it circles the globe from pole to pole. SERB will rely on its dawn-to-dusk orbit to keep its solar panels facing the Sun almost constantly.

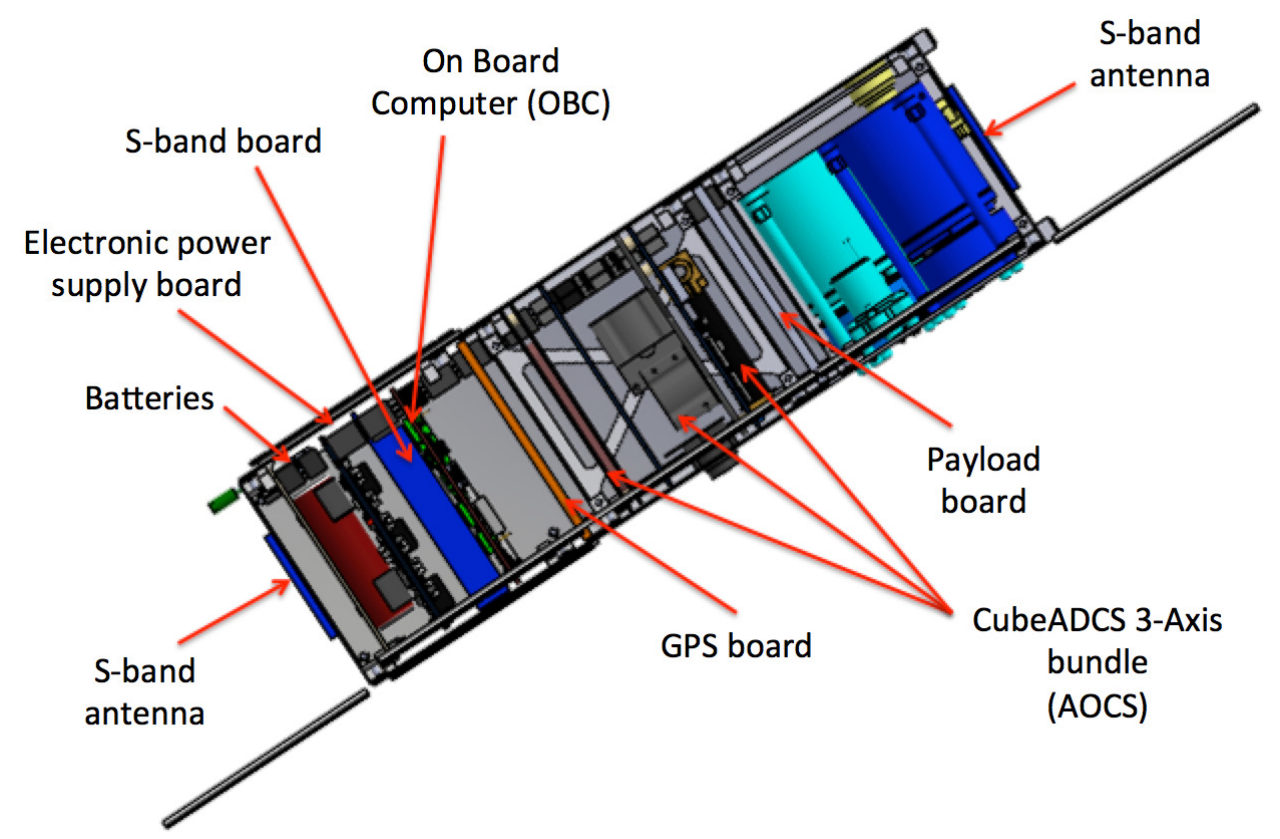

Figure 5. Location of the main components of the SERB nano-satellite.

\subsection{Detailed mass budget}

The maximum mass of the SERB nano-satellite is $4.5 \mathrm{~kg}$ as seen in Table 2.

Table 2. Nano-satellite mass budget with margin.

\begin{tabular}{|l|l|l|l|}
\hline Component & Mass $[\mathrm{kg}]$ & Margin $[\%]$ & Mass with margin $[\mathrm{kg}]$ \\
\hline Batteries & 0.46 & 5 & 0.48 \\
Electronic power supply board & 0.31 & 5 & 0.33 \\
S-band board & 0.40 & 5 & 0.42 \\
On board computer (NINANO) & 0.12 & 5 & 0.13 \\
GPS board, antenna, and harness & 0.06 & 10 & 0.07 \\
CubeADCS 3-Axis bundle & 0.46 & 10 & 0.51 \\
S-band patch antenna (x2) & 0.16 & 5 & 0.17 \\
Payload board & 0.19 & 10 & 0.21 \\
Payload and harness & 0.73 & 20 & 0.88 \\
Structure, solar panels, harness, etc. & 1.20 & 10 & 1.32 \\
\hline Total & 4.09 & - & 4.52 \\
\hline
\end{tabular}




\subsection{Detailed electrical power budget}

The detailed electrical power budget of the SERB nano-satellite is shown in Table 3. Power consumption with margin of the SERB nano-satellite is less than $13.6 \mathrm{~W}$.

Table 3. Detailed power consumption of the SERB nano-satellite.

\begin{tabular}{|l|l|l|l|}
\hline Component & Power $[\mathrm{W}]$ & Margin [\%] & Power with margin [W] \\
\hline Batteries & 0.11 & 10 & 0.12 \\
Electronic power supply board & 0.36 & 10 & 0.40 \\
S-band board & 2.82 & 10 & 3.10 \\
On board computer (NINANO) & 3.10 & 10 & 3.41 \\
GPS board and antenna & 0.80 & 10 & 0.88 \\
CubeADCS 3-Axis bundle & 0.80 & 10 & 0.88 \\
S-band patch antenna (x2) & - & - & - \\
Payload board & 0.97 & 10 & 1.07 \\
Payload and harness & 3.37 & 10 & 3.71 \\
Structure, solar panels, harness, etc. & - & - & - \\
\hline Total & 12.33 & - & 13.57 \\
\hline
\end{tabular}

\subsection{Description of the main components of the SERB platform nano-satellite}

\subsubsection{Structure of the nano-satellite and solar panels}

The structure will be carried out with aluminium. Stainless steel tie-rods will be used to support all electronic boards of the SERB nano-satellite. Moreover, all materials (A7075 aluminium for the structure, steel screw for all the fasteners, polyimide printed circuit board, etc.) and coating selection (black paint, white paint, alodine, black anodization, etc.), must be compliant with specific requirements such as total mass loss (TML) less than $1 \%$ and collected volatile condensable material (CVCM) less than $0.1 \%$, according to guidelines for spacecraft cleanliness control (ESA-PSS-51 European Space Agency).

The nano-satellite will use a minimum of 22 cells on deployable solar panels. $30 \%$ triple junction GaAs solar cells from AzurSpace (Germany) will be used. During the solar pointing mode (June solstice), the average power generated is $\sim 19 \mathrm{~W}$ (see Table 4 ), which is much greater than the nano-satellite power consumption (13.6 W). The SERB nano-satellite is on a SSO orbit at an altitude of $680 \mathrm{~km}$, allowing continuous observations of the Sun, except for short periods during a November-January "eclipse season" when the Earth comes within the nano-satellite payload line-of-sight once per orbit. During this period, the orbit average power generated is near $15 \mathrm{~W}$ (eclipse duration $\sim 20 \mathrm{mn}$ ). In order to show than the power budget is sustainable, an initial depth of discharge (DoD) of the batteries of $10 \%$ is assumed and it can be seen that at the start of the next orbit the DoD is recovered to less than $10 \%$, meaning a minimum power budget. Therefore, the minimum power generated by the nano-satellite during the "eclipse season" is near $13.6 \mathrm{~W}$, which is compliant with the nano-satellite power consumption (Table 3).

Table 4. Typical power allowable for observations - June solstice (Solar flux of $1320 \mathrm{Wm}^{-2}$ and albedo of 0.3 ).

\begin{tabular}{|l|l|}
\hline Parameter & Values \\
\hline Solar panel section (one element) & $30.18 \mathrm{~cm}^{2}$ \\
Solar panel location and cells number & 22 cells \\
Cells efficiency & $\sim 0.28$ \\
EPS efficiency & $\sim 0.9$ \\
Incident power & $75.2 \mathrm{~W}$ \\
Minimum power generated & $18.9 \mathrm{~W}$ \\
\hline
\end{tabular}




\subsubsection{Electronic power supply board and batteries}

For the EPS board, we have two options. Nowadays, the nominal solution is the one proposed by the Clyde Space company. Clyde space third generation (3g) electronic power supply for higher-power cubesats could be used. It is suitable for cubesats with deployable solar panels such as the SERB nano-satellite. Main typical features of the Clyde Space 3g EPS are:

- $1 \times 3 \mathrm{~W}$ and $8 \times 12 \mathrm{~W}$ battery charge regulators,

-3.3V (@4.5 A), 5V (@4.5 A), 12 V (@1.5 A), and raw battery voltage (@4.5 A) buses,

- Watch-dog timer ensures system reboot if no new commands are received after a selectable time period,

- Inclusion of 10 latch-up current limiter (LCL) switch channels on motherboard to switch payloads on and off as required,

- Bus over-current, battery over/under-voltage protection,

- Universal serial bus (USB) battery charger for ground testing as part of the platform umbilical,

- And separation switch.

The EPS board shall distribute power through the interface in groups of $3.3 \mathrm{~V}, 5 \mathrm{~V}, 12 \mathrm{~V}$, and power of the battery. Furthermore, the SERB nano-satellite will use the VES16 batteries that are specially adapted for space applications. Main typical performances of the Saft VES16 battery are a nominal capacity of $4.5 \mathrm{Ah}$, a mean voltage of $3.6 \mathrm{~V}$, and an energy around $16 \mathrm{Wh}$.

\subsubsection{S-band telemetry (TM) and tele-command (TC) transceiver}

The SERB payload can be embarked on very small platform but it requires to download a large volume of data with a high telemetry bit rate subsystem. The EWC31 S-band transceiver module for nano-satellite (Syrlinks, France) will be used. For the TM, the equipment operates in the $2200-2290 \mathrm{MHz}$ range. The radio frequency (RF) output power can be adjusted from +27 to $+33 \mathrm{dBm}$ (at duplexer output) with data rates from $10 \mathrm{kbps}$ to 1 Mbps. For the TC, the equipment operates in the $2025-2110 \mathrm{MHz}$ frequency range at a data rate, which can be selected from $8 \mathrm{kbps}$ to $256 \mathrm{kbps}$. Nominal power consumption (TC) is close to $1.2 \mathrm{~W}$ typical. Power consumption (TM and TC) is less than $12 \mathrm{~W}$ for $+33 \mathrm{dBm}$ RF output power that represents no more than $15 \%$ during an orbit (link with the ground-based S-band antenna).

\subsubsection{SERB on board computer}

OBC will be provided by Steel Électronique (France). The NINANO (Numeric Intensive Node for Applications mono-module adaptation for nano-satellites) OBC will be used. Main Steel Électronique OBC internal features are: 1 Gbyte DDR3 (Double Data Rate type three), 8 Kbyte FRAM (Ferroelectric Random-Access Memory), 16 Mbyte QSPI (Quad-Serial Peripheral Interface) flash for boot loader and programmable logic (PL) configuration, 8 Gbits NAND (Negative-AND) flash for data storage (PS) or 128 Gbits if handled by PL, and $33.33 \mathrm{MHz}$ ultra-stable Crystal Oscillator (XO). Indeed, the ultra-stable crystal oscillator is required to have a knowledge of the time acquisition with a high accuracy.

\subsubsection{Global positioning system board and antenna}

We will use the GPS electronic board and the antenna sold by Surrey Satellite Technology (SSTL). Thus, SERB positioning and timing information can be processed to obtain orbital information. Main typical performance of the SSTL Space GPS Receiver (SGR-05U) is a knowledge of the nano-satellite position at 10 meters (at 95\% confidence levels). The knowledge of the satellite position is required to determine the Earth-Sun distance and to achieve a radiation budget of the Earth with high accuracy. In addition, the SSTL antenna (weighing $12 \mathrm{~g}$ with $13 \times 13 \times 40 \mathrm{~mm}$ dimensions) will be used. 


\subsubsection{Orbit and active attitude control: the CubeADCS 3-Axis bundle}

The Attitude Determination and Control System (ADCS) chosen for the SERB mission is a 3-Axis ADCS bundle developed by the Electronic Systems Laboratory (ESL) of Stellenbosch University (South Africa). It provides attitude sensing and control capabilities to the nano-satellite. The unit consists of three subsystems integrated into a compact bundle as seen in Figure 6 .

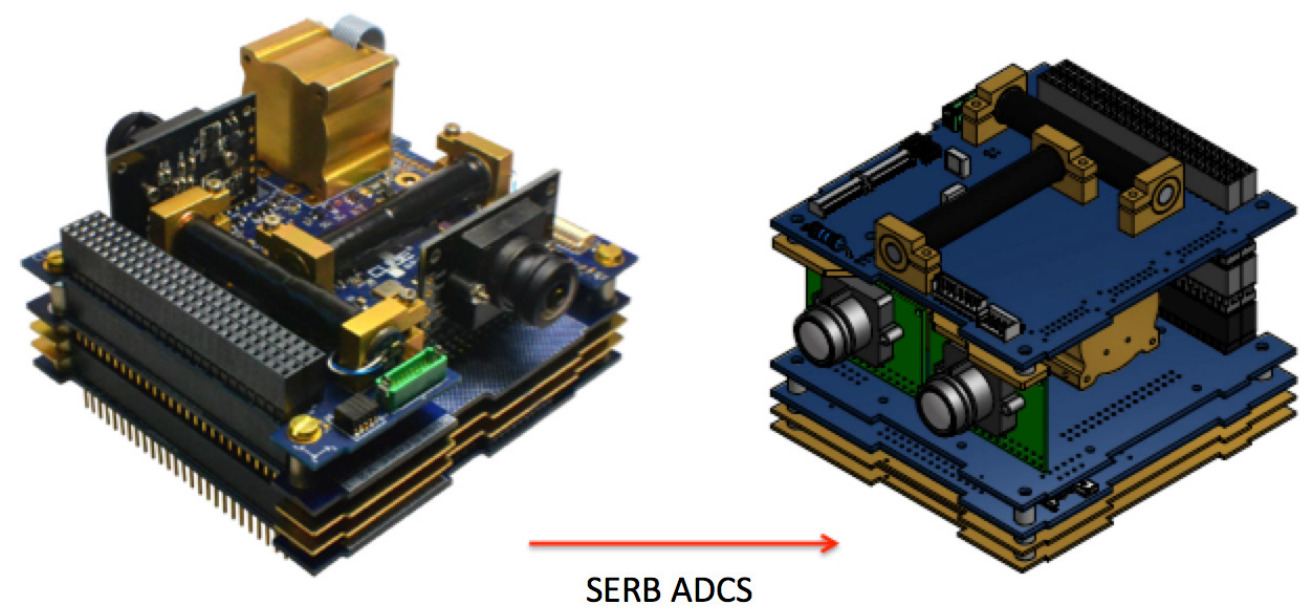

Figure 6. (left) Standard CubeADCS 3-Axis bundle. (right) Solution for the SERB CubeADCS 3-Axis bundle. Credits: Stellenbosch University (South Africa).

The first module is a sensor module that interfaces with two magnetometers (one deployable and one redundant) and ten coarse solar sensors mounted on each face of the nano-satellite. The second module is a Sun and nadir sensor that uses two cameras with a $160^{\circ}$ field of view. The third module is a generic CubeSat on-board computer and the last module is composed of three reaction wheels magnetically shielded and mountable in three axes. This bundle should be able to match the precision requirements of the nano-satellite, and to stay within reasonable mass and power budget.

There are three modes of active attitude control (AAC):

- Sun pointing: the platform is three-axes stabilised. ADCS is required to provide a pointing accuracy of $\pm 0.2^{\circ}$ for the -Z-axis of the nano-satellite (along the payload line of sight) and a stability of 30 arc-seconds per second of the $\mathrm{X}$ and $\mathrm{Y}$-axis. This level of performance is higher than the performance that is guaranteed by a standard nano-satellite platform.

- Nadir pointing: the -Z-axis of the nano-satellite is pointed towards the Earth (payload line of sight) with an accuracy better than $0.4^{\circ}$.

- Stars pointing: the $-\mathrm{Z}$ axis of the nano-satellite is pointed towards the stars during a short period. This is the method of calibration of our instruments (reference with the cold space).

\subsection{Description of the main components of the SERB payload}

The payload encompasses four instruments in a $10 \times 10 \times 10 \mathrm{~cm}^{3}$ space. Payload instruments are:

- A solar radiometer (SR) of new instrumental design, used for the measurement of the total solar irradiance,

- Two Earth radiometers (ER1 and ER2) that measure OLR radiations (IR flux) and shortwave radiations (albedo) of the Earth,

- A UV solar photometer (SP) to measure the Herzberg solar continuum (200-242 nm),

- And a SERB camera (SC). 


\subsubsection{Description of the solar radiometer of the SERB payload}

A solar radiometer (SR) of new instrumental design (Figure 7) will be used for the TSI measurement. It covers the spectral range 0.2 to $3 \mu \mathrm{m}$, with a mass of $0.32 \mathrm{~kg}$, and with dimensions of $47 \mathrm{~mm}$ diameter by $95 \mathrm{~mm}$ length.

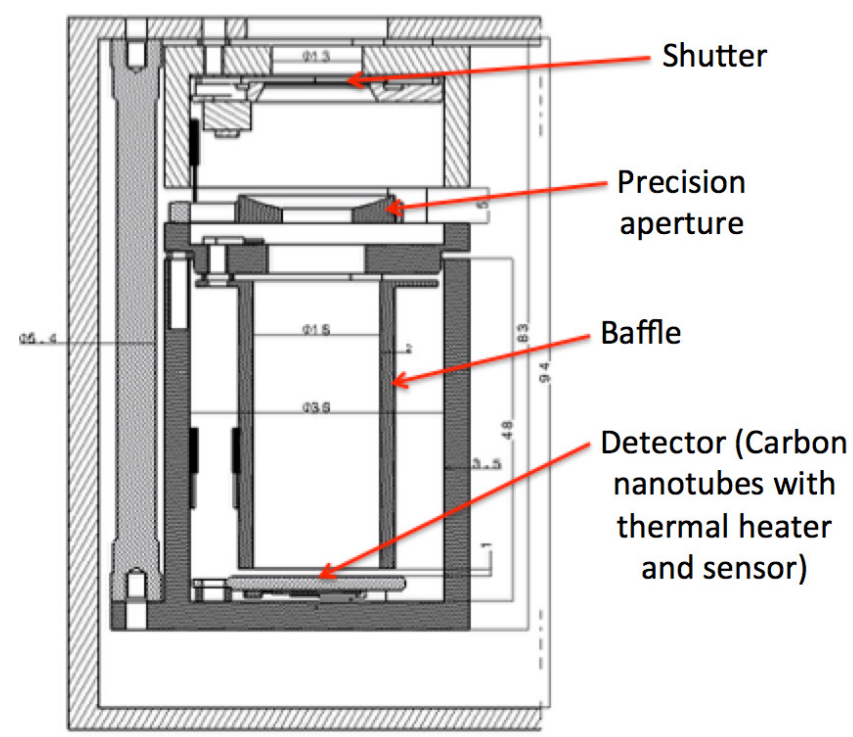

Figure 7. Main design of the SERB solar radiometer.

\subsubsection{Description of the solar photometer of the SERB payload}

A solar photometer (SP) of new instrumental design (Figure 8) will be used for the SSI measurement at $215 \mathrm{~nm}$. The maximum mass of the SP photometer is close to $0.36 \mathrm{~kg}$ and with dimensions of $50 \mathrm{~mm}$ diameter by $95 \mathrm{~mm}$ length.

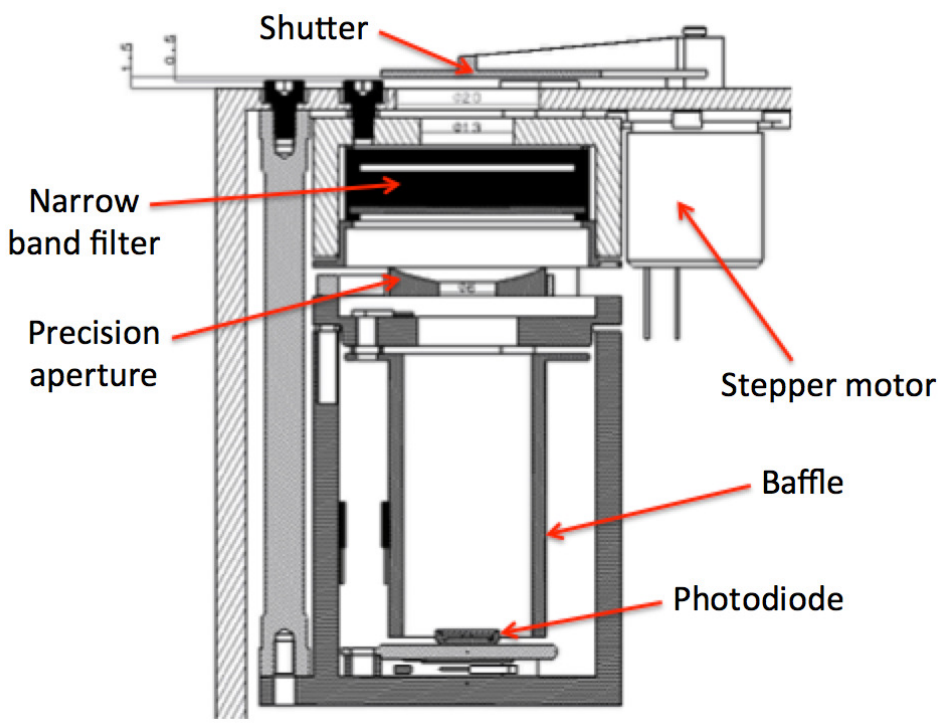

Figure 8. Main design of the SERB solar photometer. 


\subsubsection{Description of the Earth radiometers of the SERB payload}

Two Earth radiometers (ER1 and ER2) are simple systems (Figure 9) with a mass of $0.03 \mathrm{~kg}$ each, covering 0.2 to $100 \mu \mathrm{m}$ spectral range and with maximum dimensions of $22 \times 22 \times 22 \mathrm{~mm}^{3}$.

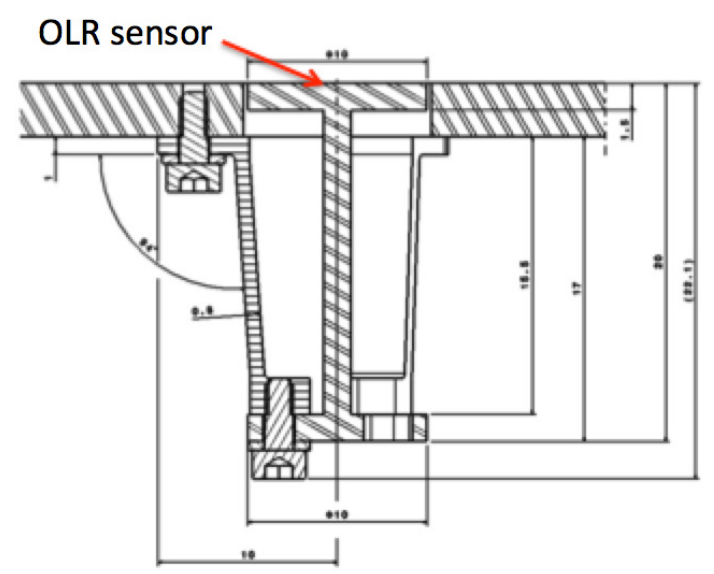

Figure 9. General view of the ER1 Earth radiometer.

\subsubsection{Description of the camera of the SERB payload}

The SERB nano-satellite will also use a charge-coupled device (CCD) with its optic, which represents the SERB camera (SC). SC role is to take images of the Earth in the VIS or in the NIR spectra. The main features are:

- A mass of $0.13 \mathrm{~kg}$ (with margin),

- A power consumption of $1.9 \mathrm{~W}$ (with margin),

- A volume of $53 \times 36 \times 66 \mathrm{~mm}^{3}$,

- A 1 Mega pixels CCD detector,

- and an optic with $32^{\circ}$ wide field of view.

\subsection{Flight software}

The flight software includes several tasks, which are:

- Supervisor task: to ensure in case of contingency actions are taken,

- Flight planner: provide time stamped instructions to the system,

- Timekeeping task: to track and log time and events,

- Housekeeping task: to collect housekeeping data,

- Localisation task: to transmit a simple beacon to locate the nano-satellite,

- Downlink task: to downlink housekeeping and payload data,

- AOCS task: to set the attitude and orbit control mode and orientation of the nano-satellite,

- Payload software task: communication between the payload and the OBC. 


\subsection{Link budget of the nano-satellite}

Communication system has been analysed and link budget was calculated. The Downlink volume (S-band) is less than 400 Mbyte per day. There is $\sim 6$ visible passages per day of the nano-satellite by the ground-based antenna (located in France) as shown in Figure 10. During each passage, the visibility of the nano-satellite is less than 10 minutes. Thus, it is possible to empty the whole TM with a downlink speed (S-band) of 1 Mbps. This work is in progress.

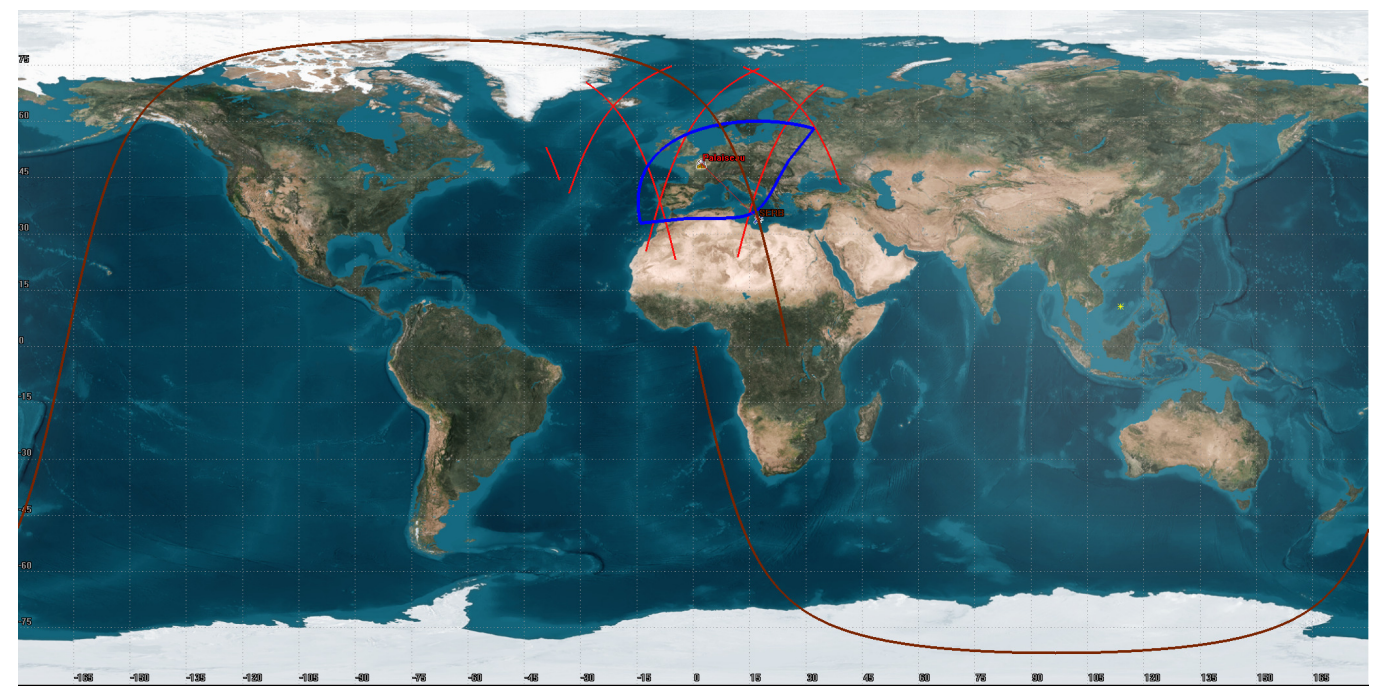

Figure 10. Visibility of the SERB nano-satellite by the ground-based S-band antenna (Palaiseau, France).

\section{CONCLUSION}

The role of nano-satellites for education is well established. Space sciences remain very attractive for young people interested in new technologies. The SERB project was conducted by students. Lately, we have seen a new interest in space exploration grow in the public. Such interest was unseen since the end of the seventies, and one of the consequences is that more and more students want to work in space engineering. In this regard, nano-satellites provide an excellent way for students to introduce themselves to the vast world of space missions and real world engineering projects, requiring skills in design and conception, but also in management and communication.

As for the core scientific principles of such missions, the relatively low cost of nano-satellites allows for components with low technical maturity to be sent in orbit for evaluation purposes. CubeSat missions provide a cheap way to test instruments in real conditions before sending them on more complex and more expensive orbits.

Even then, it would be unfair to call such missions "simple". The SERB project is a prime example of an ambitious scientific goal pursued by a nano-satellite. As such, it is a perfect example of a cost-effective mission focusing on technological research and commercial proof-of-concept. This project was enabled through the joint effort of a multidisciplinary consortium of partners, including academic research, institutions, and industries. This enables us to precisely control the framework for implementation and costs, since the nano-satellite will be developed using units of already qualified subsystems from our industrial partners.

In summary, this mission will allow to measure TSI variability and to extend previous measurements, to improve the knowledge of the TSI absolute value with an accuracy better than $0.5 \mathrm{Wm}^{-2}$, to establish a radiation budget of the Earth with an accuracy better than 5\%, and to monitor SSI at $215 \mathrm{~nm}$ (Herzberg solar continuum). Such missions bring forth a new horizon of exciting possibilities: constellation, accompanying/completing a large mission, etc. 


\section{ACKNOWLEDGMENTS}

We thank CNRS (Centre National de la Recherche Scientifique), École polytechnique, CNES, and RMIB for their support as well as all participants who have devoted their expertise to this study. In addition, we wish to thank Gérard Auvray (École polytechnique), Alain Gaboriaud (CNES), Jean-Luc Legal (CNES), Guillaume Morice (AKKA), and Professor Herman Steyn (University of Stellenbosch).

\section{REFERENCES}

1. Puig-Suari, J., Schoos, J., Turner, C., Wagner, T., Connolly, R., and Block, R., "CubeSat developments at Cal Poly: the standard deployer and PolySat," in [Small Payloads in Space], Horais, B. J. and Twiggs, R. J., eds., Society of Photo-Optical Instrumentation Engineers (SPIE) Conference Series 4136, 72-78 (Nov. 2000).

2. Twiggs, R. J., "Space system developments at Stanford University: from launch experience of microsatellites to the proposed future use of picosatellites," in [Small Payloads in Space], Horais, B. J. and Twiggs, R. J., eds., Society of Photo-Optical Instrumentation Engineers (SPIE) Conference Series 4136, 79-86 (Nov. 2000).

3. Foukal, P., Fröhlich, C., Spruit, H., and Wigley, T. M. L., "Variations in solar luminosity and their effect on the Earth's climate," Nature 443, 161-166 (Sept. 2006).

4. Foukal, P., "A New Look at Solar Irradiance Variation," Solar Physics 279, 365-381 (Aug. 2012).

5. Vieira, L. E. A., Solanki, S. K., Krivova, N. A., and Usoskin, I., "Evolution of the solar irradiance during the Holocene," Astronomy \& Astrophysics 531, A6 (July 2011).

6. Kopp, G. and Lean, J. L., "A new, lower value of total solar irradiance: Evidence and climate significance," Geophys. Res. Lett. 38, 1706 (Jan. 2011).

7. Schmutz, W., Fehlmann, A., Finsterle, W., Kopp, G., and Thuillier, G., "Total solar irradiance measurements with PREMOS/PICARD," in [American Institute of Physics Conference Series], American Institute of Physics Conference Series 1531, 624-627 (May 2013).

8. Meftah, M., Dewitte, S., Irbah, A., Chevalier, A., Conscience, C., Crommelynck, D., Janssen, E., and Mekaoui, S., "SOVAP/ Picard, a Spaceborne Radiometer to Measure the Total Solar Irradiance," Solar Phys. 289, 1885-1899 (May 2014).

9. Yeo, K. L., Krivova, N. A., Solanki, S. K., and Glassmeier, K. H., "Reconstruction of total and spectral solar irradiance from 1974 to 2013 based on KPVT, SoHO/MDI, and SDO/HMI observations," Astron. Astrophys. 570, A85 (Oct. 2014).

10. Dewitte, S., Crommelynck, D., and Joukoff, A., "Total solar irradiance observations from DIARAD/VIRGO," Journal of Geophysical Research (Space Physics) 109, 2102 (Feb. 2004).

11. Barkstrom, B., Harrison, E., Smith, G., Kibler, J., and Green, R., "Earth Radiation Budget Experiment (ERBE) archival and April 1985 results," Bulletin of the American Meteorological Society 70, 1254-1262 (Oct. 1989).

12. Hansen, J., Sato, M., Kharecha, P., and von Schuckmann, K., "Earth's energy imbalance and implications," Atmospheric Chemistry \&O Physics Discussions 11, 27031-27105 (Sept. 2011).

13. Martin-Puertas, C., Matthes, K., Brauer, A., Muscheler, R., Hansen, F., Petrick, C., Aldahan, A., Possnert, G., and van Geel, B., "Regional atmospheric circulation shifts induced by a grand solar minimum," Nature Geoscience $\mathbf{5}$, 397-401 (June 2012).

14. Haigh, J. D., Winning, A. R., Toumi, R., and Harder, J. W., "An influence of solar spectral variations on radiative forcing of climate," Nature 467, 696-699 (Oct. 2010). 